world's oceans. Satellite missions being studied in his laboratory of relevance to CLIVAR include remotely sensed approaches to monitor global sea surface salinity and soil moisture. Dr. Busalacchi has received numerous awards internal and external to NASA. Among these, in 1991, he was the recipient of the Arthur S. Flemming Award, as one of five outstanding young scientists in the US Federal Government. In 1995 he was selected as Alumnus of the Year at Florida State University, in 1997 he was the H. Burr Steinbach Visiting Scholar at the Woods Hole Oceanographic Institution, and in 1999 he was recognized by President Clinton in receiving the Presidential Rank Meritorious Executive Award.

\section{The First International Conference on the Ocean Observing System for Climate:}

\section{A new era for ocean observation}

\section{Neville Smith}

Bureau of Meterology Research Centre, Melbourne, Australia

N.Smith@bom.gov.au

\section{Chet Koblinsky}

Goddard Space Flight Center, NASA, Greenbelt, USA

koblinsky@gsfc.nasa.gov

Oceanography is at a critical stage. A new era may be on the horizon with observations implemented globally and fully integrated to serve a broad range of requirements from the extensive research demands of CLIVAR to more immediate operational applications. In order to attain this vision, the ocean community must resolve to act with common and agreed purpose and work strategically over the coming decades.

The first International Conference on the Ocean Observing System for Climate held in Saint Raphael, France 18-22 October, sought the consensus needed to initiate this step, addressing the collective needs of both research and operational oceanography. The Conference was bold in its vision and goals, successfully developing a broadly based and sound scientific rationale for the establishment of a sustained system. CLIVAR research themes, practical El Niño forecasts, climate change detection, and ocean and marine forecasts were prominent rationale.

The Conference was purposefully structured with 40 solicited presentations and 5 round table discussions to encourage consideration of, and agreement on, the value of a multi-purpose, integrated system. This value was evident in many of the 160 contributed papers presented in the poster sessions, for example, the wide application of altimeter and wind vector measurements and in the many considerations of complementary data streams. The conference agenda, all of the solicited papers, the conference statement, and a section for community feedback, which is ongoing, can be found at the website: http: / / www.bom.gov.au/OceanObs99/. We welcome your comments.

The Conference explicitly considered issues of cost and returns on investment. Highest priority was attached to those elements that were perceived to be reliable, efficient and sustainable, from the perspective of delivering both short and long-term value for the investment. Proven methodologies were preferred to emerging or potential techniques. However, presentations on emerging technologies highlighted the need for agility in long term planning to accommodate advanced technologies, a broader measurement suite, observation efficiency, and improved economy in the future.

Remote sensing has become a mature technology for collecting regular, global observations. Sea surface temperature, surface wind vectors, surface wave height and surface topography can all be measured with reliability from space. The Conference agreed that for a global system such capacity is fundamental. Continuity was seen as a major issue in order to meet the CLIVAR research requirements for multidecadal data, as well as sustained operational requirements. A plenary round-table discussion highlighted the need to develop effective strategies for the transition of proven experimental techniques into a sustainable, operational mode.

Somewhat surprisingly, sea surface temperature emerged as an important future issue. In order to meet requirements, a more effective integration of available data must be achieved. It was less surprising that strategies to improve the currently available salinity measurements came up in many presentations.

A multi-faceted, robust in situ network must also be implemented, in part as a complement to, and validation for, remotely sensed data, but also for its own intrinsic value in various applications. The primary contributions include

- The tropical Pacific ENSO Observing System and its mooring array;

- The global array of profiling floats, Argo, returning around 100,000 profiles of temperature and salinity annually;

- A global surface drifter array and surface and subsurface networks operated from voluntary observing vessels;

- Surface and subsurface reference sites, such as provided by sea level stations and fixed-point deep measurements;

- Hydrographic measurements targeting the carbon cycle and the deep ocean circulation; and

- Acoustic tomography in selected high latitude regions.

These contributions would be supported by a program of dedicated enhancements in areas of high priority, for example PIRATA in the tropical Atlantic. Strategies for under-observed regions, such as the Indian Ocean, are anticipated outcomes from CLIVAR.

The development of a new paradigm for oceanography was one of the major achievements of the Conference. Free and wide availability of all data and products need to become the norm, not the exception. Significant challenges remain for many aspects of data and information management but none are regarded as insurmountable obstacles to progress.

While the focus of the Conference was on measurement networks, all participants recognized the fundamental importance of models and data assimilation to the progress, prosperity and evolution of the observing system. 
The new paradigm is fashioned around the use of models to interpret and exploit data and to develop products that encourage wide adoption and value-adding.

The degree of unanimity achieved by the Conference exceeded expectations, yet there is clearly much work remaining, both in terms of detail and in terms of enacting the recommendations. However the ocean community can look forward with some confidence to an era of great prospect and opportunity, and also one of enhanced responsibility. For oceanography and climate at least, the integrated global observing strategy is now being realized.

\section{Science Highlights from the Monsoon Sym- posium and CLIVAR Monsoon Panel Meeting}

\section{William K.-M. Lau}

Goddard Space Flight Center, NASA, Greenbelt, USA

lau@climate.gsfc.nasa.gov

The CLIVAR Asian-Australian (AA) Monsoon Panel held its second official meeting on December 8-10, 1999 at the EastWest Center, Honolulu, Hawaii. The panel meeting was preceded by a 2-day (Dec. 6-8) Monsoon Symposium to celebrate the careers of Profs. T. Murakami, and M. Yanai who are now both retired. The first day of the panel meeting was devoted to a Model Intercomparison Workshop, sponsored by the CLIVAR AA-Monsoon Panel in response to the CLIVAR SSG's call for focused efforts to improve our understanding of the causes and consequences of the massive ENSO disturbances of 1997-1998. Results were presented showing Atmospheric General Circulation Model (AGCM) performance in simulating monsoon circulation, for given Sea Surface Temperatures (SSTs). Further presentations examined the performance of Oceanic General Circulation Models (OGCMs) in simulating the observed SST anomalies (SSTAs), given observed or estimated surface fluxes. A summary of scientific highlights presented at the meetings are as follow:

- The monsoon is a coupled ocean-atmosphere-land phenomenon. Modelling and prediction of the monsoon and its variability requires the inclusion of all three components. In particular, the annual cycle of heat balance and oceanic transports in the Indian Ocean play a significant role in the annual cycle of the monsoon.

- Variability of the monsoon is influenced by, and probably influences, the ENSO phenomenon. However, the relationships are spasmodic and vary on interdecadal time scales.

- Intrinsic coupled monsoon rainfall-SST modes have been identified in the western Pacific and the Indian Ocean that contribute significantly to variability of monsoon intensity. Understanding of the physical make-up of these modes is crucial in unravelling fundamental mechanisms of monsoon-ENSO relationships.

- $\quad$ Regarding the existence of a strong biennial variability of the monsoon, a number of theories have been proposed invoking feedbacks between the land, ocean and atmosphere of the monsoon regime extending from the western Pacific Ocean, the Asian land mass and the Indian Ocean. However, like the ENSO-monsoon relationship, there appears to be interdecadal variability of the biennial signal.

- There are new findings suggesting that the Indian Ocean possesses coupled ocean-atmosphere modes that may be independent of ENSO. One of these modes occurs in the form of an oscillating east-west dipole in SST and precipitation. Whereas the relationship to monsoon variability is unclear, it is strongly correlated with the East African fall monsoon rains.

- New evidence suggests that regional components of the monsoon, i.e. the South Asian and the East Asian monsoons oscillate between active and break phases, which are related to intraseasonal oscillations on 40-60 day time scales. These fluctuations are associated with the "Madden-Julian oscillation" (MJO) but are modified by the strong north-south pressure gradient and basin-scale SST fluctuations that exist during the established monsoon. While the ISO may limit interannual monsoon predictability, it offers great promise for short-term ( weeks) monsoon forecasts.

- Interesting and significant results are coming out from recent field experiments e.g., SCSMEX, JASMINE and BOBMEX. For example, preliminary results from JASMINE indicates that the ocean-atmosphere heat flux during the established monsoon in the southern Bay of Bengal region is similar to the mean heat flux in the tropical Pacific warm pool. The variability of surface fluxes on intraseasonal time scales in the eastern Indian Ocean is very large, suggesting strong local air-sea interaction.

Deliberations at the Hawaii Panel Meeting provided a number of recommendations for action in the areas of modelling, process studies and long-term monitoring. These recommendations form the basis of a CLIVAR Monsoon Implementation Plan, which is being developed. For a preliminary draft of the Implementation Plan, please check the website http: / / climate.gsfc.nasa.gov/ kmkim/clivar /

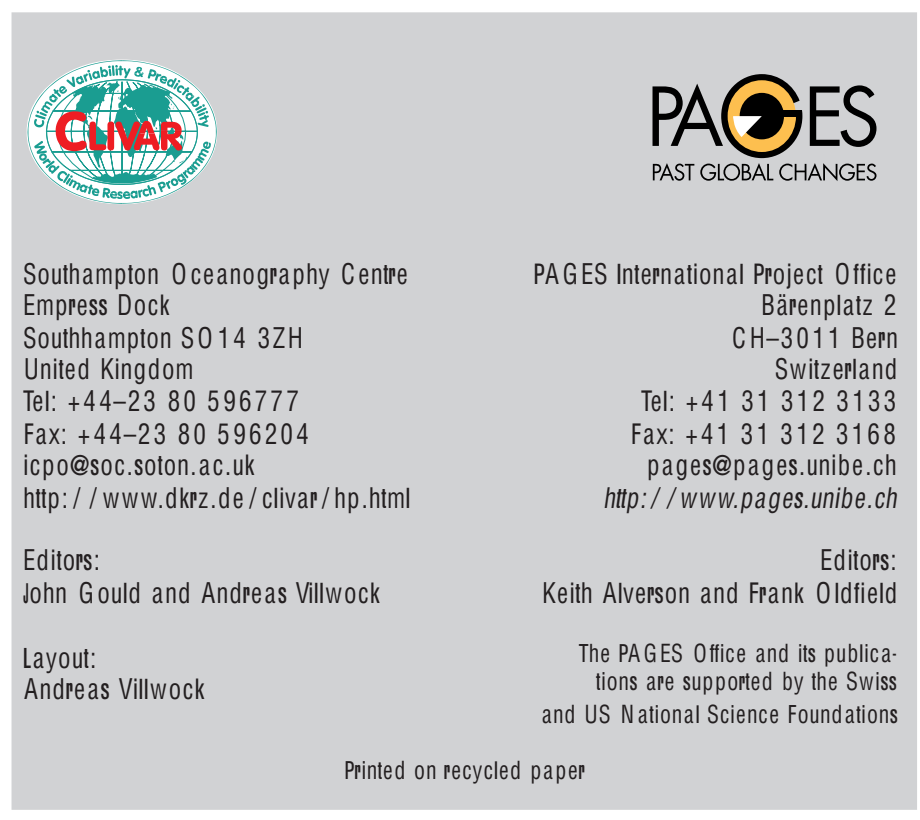

